\title{
Quantitative Imaging and In Situ Concentration Measurements of Quantum Dot Nanomaterials in Variably Saturated Porous Media
}

\author{
Burcu Uyuşur,, ${ }^{1}$ Preston T. Snee, ${ }^{2}$ Chunyan Li, ${ }^{3}$ and Christophe J. G. Darnault ${ }^{3}$ \\ ${ }^{1}$ Tübitak Marmara Research Center, P.K. 21, Gebze, 41470 Kocaeli, Turkey \\ ${ }^{2}$ Department of Chemistry, University of Illinois at Chicago, 845 West Taylor Street, Chicago, IL 60607, USA \\ ${ }^{3}$ Department of Environmental Engineering and Earth Sciences, Laboratory of Hydrogeoscience and Biological Engineering, L. G. Rich \\ Environmental Laboratory, Clemson University, 342 Computer Court, Anderson, SC 29625, USA
}

Correspondence should be addressed to Christophe J. G. Darnault; cdarnau@clemson.edu

Received 30 June 2015; Revised 28 November 2015; Accepted 7 December 2015

Academic Editor: Victor M. Castaño

Copyright (C) 2016 Burcu Uyuşur et al. This is an open access article distributed under the Creative Commons Attribution License, which permits unrestricted use, distribution, and reproduction in any medium, provided the original work is properly cited.

\begin{abstract}
Knowledge of the fate and transport of nanoparticles in the subsurface environment is limited, as techniques to monitor and visualize the transport and distribution of nanoparticles in porous media and measure their in situ concentrations are lacking. To address these issues, we have developed a light transmission and fluorescence method to visualize and measure in situ concentrations of quantum dot (QD) nanoparticles in variably saturated environments. Calibration cells filled with sand as porous medium and various known water saturation levels and QD concentrations were prepared. By measuring the intensity of the light transmitted through porous media exposed to fluorescent light and by measuring the hue of the light emitted by the QDs under UV light exposure, we obtained simultaneously in situ measurements of water saturation and QD nanoparticle concentrations with high spatial and temporal resolutions. Water saturation was directly proportional to the light intensity. A linear relationship was observed between hue-intensity ratio values and QD concentrations for constant water saturation levels. The advantages and limitations of the light transmission and fluorescence method as well as its implications for visualizing and measuring in situ concentrations of QDs nanoparticles in the subsurface environment are discussed.
\end{abstract}

\section{Introduction}

Engineered nanomaterials such as carbon nanotubes, fullerenes, and metal- and semiconductor-based nanomaterials (e.g., quantum dots (QDs)) are revolutionizing science and engineering. Nanomaterials release into soil, air, and water resources following their life cycle or spills and their impacts on ecological systems are inevitable [1-3]. Ability to predict the public health and environmental impacts of the release of nanomaterials is limited [4-6]. Knowledge and data on the fate and transport of nanomaterials in the environment are sparse due to limited methods to monitor nanomaterials, especially in variably saturated porous media. Consequently, research on the fate and transport of nanomaterials in the environment, and methods to monitor them, is fundamental.

To investigate the fate and transport of nanoparticles in the subsurface environment, the common practice is to use laboratory-scale saturated or unsaturated column experiments, in which the nanoparticles are introduced from one end of the column under various solution chemistry and hydrodynamic conditions and are collected from the other end over time. Changes in the nanoparticle concentrations are usually obtained only from the end of the column with respect to time or pore volume eluted; these data are called breakthrough curves (BTCs) [6-9]. In some fate and transport experiments, the column may be segmented at the end of the experiment, and particle distribution profiles throughout the column can be obtained (e.g., $[10,11])$. The data gathered, however, are restricted to one dimension [12]. One approach being pursued for exploring the fate and transport of particles in saturated and unsaturated porous media is the use of visualization techniques (e.g., [13-17]). These techniques employ physical models that 
use a two-dimensional chamber packed with porous media subject to flow and transport simulation and exposed to light sources. The common visualization methods to monitor particle transport in porous media include visible light using fluorescent or UV light epifluorescence imaging, time lapse fluorescence imaging, magnetic resonance, and X-rays [1821]. The flow of water and the transport and transformation of particles are observed with a camera or sensors that record the transmitted and/or emitted light. These images are then processed with imaging software. These methods enable nonintrusive and nondestructive visualization of flow and transport processes in porous media and can directly provide qualitative and/or quantitative measurements on the fate and transport of particles in porous media, such as particle location and in situ concentration.

Among the various types of nanomaterials that can be selected for the study of transport in the subsurface environment, semiconductor QDs are important subjects of investigation for several reasons. QDs were developed in the 1980s, a decade before the development of other nanomaterials such as carbon nanotubes. QDs are essential to nanosciences, engineering, and technology and are used in biology, medicine, and industry due to their optical and electronics properties [2, 22]. QDs are used as fluorescent probes for imaging of biological systems due to their broad absorption and narrow emission spectra [23-28]. QDs are photoluminescent nanocrystals with diameters varying from 2 to $100 \mathrm{~nm}$ [29], with their size and composition governing their optical properties and fluorescence over UV to nearIR wavelengths [30-33]. The size dependence of the atomiclike electronic state energies and nearly perfect luminescent characteristics of QDs are due to the effects of quantum confinement, essentially the change of the kinetic energy of localized electrons or holes via the Heisenberg Uncertainty Principle [11, 23, 34-38]. Core/shell QDs are nanocrystals that have higher photoluminescence quantum yields compared to uncoated QDs. Cadmium selenide (CdSe) QDs fluoresce in the visible light spectrum [27]. The potential prevalence of QD nanomaterials in future commercial products such as televisions $[39,40]$ represents a potentially significant increase in environmental loading of QDs. Most importantly, QDs can serve as an ideal proxy to investigate mobility and transport of nanoparticles in porous media, as their unique fluorescence properties greatly facilitate their detection and quantification within variably saturated porous media.

The objective of our research is to develop a nonintrusive visualization method capable of not only visualizing QDs but also providing in situ measurement of QDs' concentration in variably saturated porous media. This paper presents the experimental apparatus and procedures used in a visualization method that combined both light transmission and fluorescence to visualize QDs in variably saturated porous media and discusses its potential application.

\section{Experimental Apparatus and Procedures}

2.1. Quantum Dot Nanomaterials. CdSe/ZnS QDs were produced according to the procedures previously developed by researchers [30-32, 41-43]. The process of degassing
Trioctylphosphine Oxide (TOPO) was performed at a temperature of $120^{\circ} \mathrm{C}$ under vacuum and then at $360^{\circ} \mathrm{C}$ under $\mathrm{N}_{2}$ gas. A Trioctylphosphine (TOP) stock solution with Cd and Se precursors was transferred into TOPO and allowed to cool. The precipitation of QDs in solution was achieved by the addition of methanol and isopropanol. QDs were then redispersed into a degassed TOPO/TOP/decylamine solution containing cadmium complexed to tetradecylphosphonic acid. As the temperature reached $160^{\circ} \mathrm{C}$, a $\mathrm{Zn}$ and $\mathrm{S}$ precursors solution was dispersed in a TOP solution. The purification process of the core/shell QDs included precipitation with methanol and isopropanol, dispersion in chloroform, mixing with neutralized amphiphilic polymer (octylamine-modified polyacrylic acid), and solvent evaporation. The resulting dry film was then redispersed in water followed by removal of excess polymer through dialysis. The concentration of the stock suspension of green-emitting QDs that was developed $(\sim 2,000 \mathrm{ppm})$ was much higher than the lowest detection limit of the light transmission and fluorescence method (approximately $5 \mathrm{ppm}$ ). QD suspensions of different concentrations were prepared by adding deionized water to the stock suspension. All the suspensions were kept in a dark room. The peak of the emission spectra of QDs upon excitation under UV light was about $550 \mathrm{~nm}$. Because the luminescent spectra of QDs are much narrower than fluorescent organic dyes, QDs have near unit quantum yields, are highly resistant to photobleaching, and are therefore photochemically stable.

2.2. Porous Media. Ottawa sand, a nonporous quartz silica sand of $0.7 \mathrm{~mm}$ (20/30 US std sieve size) grain size, was selected as soil porous medium because of its translucence and other optical properties and previous application in light transmission methods $[44,45]$. The physical and chemical properties of this sand are well established [46]. In all the experiments, the working sand was washed with deionized water to remove fine particles.

2.3. Light Transmission and Fluorescence Method. Color can be represented in two common formats: red, green, and blue (RGB) or hue, saturation, and intensity (HSI). In RGB color format, the amplitudes of red, green, and blue for a particular color can each range from 0 to 100 percent of full brilliance. In HSI format, hue is the color of an object, saturation is the amount of pure white in the color, and intensity represents the brightness of an object [44, 47, 48]. The HSI format is representative of how humans see color [47]. If differences in intensity and color of various concentrations of QDs in variably saturated porous media can be observed by the human eye, these differences can therefore be quantified using HSI analysis. Previous experiments have demonstrated that, in variably saturated porous media, light intensity is proportionally related to porous media saturation or liquid content [49]. In oil-water saturated porous media and oilwater-air saturated porous media in which the water is colored blue, hue is related to water content $[44,45]$. Thus, we can expect that in a variably saturated porous medium containing a wide range of QD concentrations, hue and intensity values can quantify water saturations and QD concentrations. The light transmission and fluorescence method (LTFM) 


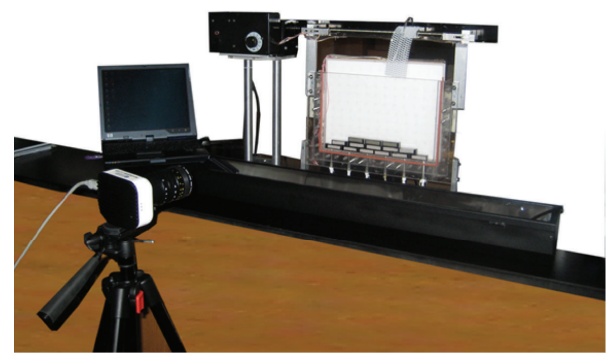

FIGURE 1: Experimental setup.

was therefore developed to visualize and provide in situ concentration measurements of QDs in variably saturated porous media.

The LTFM experimental setup includes two-dimensional calibration cells packed with porous media, a fluorescent light source, a UV light, a lens, a camera, and image acquisition and analysis software (Figure 1). Experiments were performed in a dark room at a constant temperature of $20^{\circ} \mathrm{C}$. For QD in situ concentration measurements in variably saturated porous media, the LTFM involves placing a two-dimensional chamber filled with sand porous media and a QD suspension in front of a fluorescent light source. The emitted light resulting from exciting QDs with a UV light placed in front of the chamber is captured by a camera. The transmitted light resulting from a fluorescent light located behind the chamber containing the porous media and the QD suspension was also recorded by a camera. The fluorescent light source and UV light were used in an alternating manner; the resulting images were processed using image analysis software.

The fluorescent white light source was an Osram Planon (Osram, Munich, Germany) flat fluorescent light made of light-emitting diodes (LEDs) and producing a uniform high luminance from center to edge. The luminous flux was $20 \mathrm{~lm}$ and the luminous intensity was $0.3 \mathrm{~cd}$. The diagonal length and the thickness of the Osram Planon were $26.4 \mathrm{~cm}$ and $1 \mathrm{~cm}$, respectively. The fluorescent light source was mounted in the back of the experimental chamber. The UV light consisted of a fluorescent black light (Altman Stage Lighting Co., Inc. NY, USA) made of "Wood's Glass," that is, glass doped with nickel oxide, resulting in a purple color blocking all visible light above $400 \mathrm{~nm}$. The UV light dimensions were $11 \mathrm{~cm}$ high $\times 14 \mathrm{~cm}$ wide $\times 125 \mathrm{~cm}$ long, with a power of 40 watts. The UV light was placed about $10 \mathrm{~cm}$ in front of the experimental chamber.

The camera used to record images of the transmitted and emitted lights under the different light exposures was a MicroPublisher 3.3 RTV (QImaging, Surrey, BC, Canada), which is a digital charge-coupled device (CCD) color camera with high-speed real time viewing (RTV). The MicroPublisher 3.3 RTV is a high resolution camera equipped with a 3.3 million pixel sensor system $(2048 \times 1536)$ that allows a region of interest $(\mathrm{ROI})$ from $1 \times 1$ pixels up to full resolution. The MicroPublisher 3.3 RTV is able to display a full field of view with frame rates up to $30 \mathrm{fps}$. The camera was mounted on a tripod and located $0.5 \mathrm{~m}$ in front of the experimental chamber. The camera was connected through a digital interface IEEE 1394 FireWire to a computer equipped with MS Windows (Microsoft Corporation, Redmond, WA, USA) as the operating system. The image acquisition, processing, color format conversion, measurement, and analysis were performed using IPLab software (version Va.0.4, 2006) for Windows from Scanalytics, Inc. VA, USA.

Under the fluorescent light exposure, the transmitted light resulting from the variably saturated porous media containing QDs was recorded with the CCD camera in RGB format. The image was then converted from RGB to HSI format using the IPLab software; this created an image called the "intensity image" from which the intensity of light transmitted could be measured. This image is analyzed in order to visualize water in porous media and to quantify water saturations. Under the UV light exposure, the emitted light produced by the excited QDs present in the variably saturated porous media was recorded with the CCD camera in RGB format. The image was then converted from RGB to HSI format using the IPLab software to create an image, called the "hue image," from which the hue (color) of the light emitted could be measured. This image was analyzed in order to visualize QDs in variably saturated porous media and to measure in situ QD concentrations.

2.4. Calibration. To establish a calibration between hue values and QD concentrations and between intensity values and water saturations, a two-dimensional calibration system consisting of cells packed with sand porous media and known quantities of QD concentrations and water saturations was constructed. A wide range of QD suspension concentrations was derived from the green-emitting QD stock suspension. Six different concentrations of QD suspension-40, 100, 150, 200,300 , and $500 \mathrm{ppm}$-were prepared by dilution of the stock suspension of QDs using deionized water. Five different water saturations-0, 25, 50, 75, and $100 \%$-were selected. Calibration cells were plastic disposable fluorometer cuvettes (Perfector Scientific, Atascadero, CA, USA). These cuvettes were made of methacrylate (useable wavelength range: 285 to $800 \mathrm{~nm}$ ). The use of cuvettes made of methacrylate, therefore, ensures minimal wall effect of the cuvette on the visualization of QDs. Sand was packed into the cuvettes of internal dimensions $1.1 \mathrm{~cm}$ high $\times 1.1 \mathrm{~cm}$ wide $\times 4.5 \mathrm{~cm}$ long to create a two-dimensional porous matrix. The calibration cells were filled with sand to achieve porosity of 0.38 with all possible combinations of QD concentration suspensions and degrees of water saturation.

The calibration cells were then stacked and positioned horizontally along their length in the LTFM experimental system. The experimental procedure consisted of switching on the fluorescent light source to record the transmitted light through porous media while the UV light is switched off and then switching on the UV light to excite the QDs and record the emitted light of the QDs while the fluorescent light is switched off. The calibration cells were exposed successively in an alternating fashion to fluorescent light and UV light exposures; the resulting images from the transmitted and 
emitted light were analyzed by the imaging IPLab Software. For each calibration cell, the intensity value resulting from the "intensity image" obtained with the transmitted light and the hue value resulting from the "hue image" obtained with the emitted light were measured as the mean value in a rectangle containing 100 pixels. These average values were then used to establish calibration curves corresponding to water saturations and QD concentrations.

2.5. Quantum Dots Size, Surface Charges, and Stability Analysis. The sizes and surface charges of QDs in suspensions of different ionic strengths and $\mathrm{pH}$ were characterized through Dynamic Light Scattering (DLS) measurements of hydrodynamic diameter and zeta potential measurements using a NanoBrook 90Plus Zeta Particle Size Analyzer Brookhaven Instruments Corporation (Holtsville, NY). The stability of different concentrations of QDs under different ionic strength and $\mathrm{pH}$ conditions was assessed through monitoring the absorbance at $260 \mathrm{~nm}$. The stability of the QDs was calculated as the ratio of the absorbance at $260 \mathrm{~nm}$ of the QD suspensions under various chemical conditions (i.e., ionic strength and $\mathrm{pH}$ ) and the absorbance of the QD suspensions at ionic strength $5 \times 10^{-4} \mathrm{M} \mathrm{NaCl}$ or $\mathrm{pH} 6.5$ following the procedures of stability analysis of Lin et al., 2010. To assess the stability of QDs, the suspension ionic strength was adjusted with $\mathrm{NaCl}$ while the $\mathrm{pH}$ was adjusted using $0.1 \mathrm{M} \mathrm{NaOH}$ and $0.1 \mathrm{M} \mathrm{HNO}_{3}$. Four ionic strengths $\left(5 \times 10^{-4} \mathrm{M}, 5 \times 10^{-3} \mathrm{M}, 5\right.$ $\times 10^{-2} \mathrm{M}$, and $\left.0.5 \mathrm{M}\right)$ and five $\mathrm{pH}$ values $(3,4.5,5.5,6.5$, and 8 ) as well as $\mathrm{pH} 7$ and deionized water were used.

\section{Experimental Results}

3.1. QD Stability, Size, and Surface Charge. The stability of QDs was impacted by the suspension ionic strength and $\mathrm{pH}$. As the suspension ionic strength increased from $5 \times$ $10^{-3} \mathrm{M} \mathrm{NaCl}$ to $0.5 \mathrm{M} \mathrm{NaCl}$, the stability of QDs in suspension remained at or above $80 \%$, an indication of limited aggregation of the QDs. As the suspension $\mathrm{pH}$ remained above 6 , the stability of the QDs was above $80 \%$, while as the $\mathrm{pH}$ suspension decreased from 6 to 3, the stability of the QDs decreased to $17 \%$, leading to significant aggregation of the QDs. Ionic strength and $\mathrm{pH}$ impacted the zeta potential of QDs. The impact of ionic strength and $\mathrm{pH}$ on the stability of the QDs was limited as the QDs were originally coated by neutralized amphiphilic polymer (octylamine-modified polyacrylic acid). The addition of the polymer to the coating of QDs contributed to the steric repulsion forces. The presence of the polymer at the surface of QDs stabilizes them against aggregation. The average hydrodynamic diameters of QD aggregates were $411 \pm 98 \mathrm{~nm}, 528 \pm 67 \mathrm{~nm}, 305 \pm$ $73 \mathrm{~nm}$, and $656 \pm 180 \mathrm{~nm}$, respectively, for $5 \times 10^{-4} \mathrm{M} .5 \times$ $10^{-3} \mathrm{M}, 5 \times 10^{-2} \mathrm{M}$, and $0.5 \mathrm{NaCl}$. The average sizes of QD aggregates were $2180 \pm 673 \mathrm{~nm}, 223 \pm 32 \mathrm{~nm}, 308 \pm 116$, $417 \pm 115 \mathrm{~nm}$, and $506 \pm 210 \mathrm{~nm}$, respectively, for $\mathrm{pH} 3,4.5$, $5.5,6.5$, and 8. As the suspension ionic strength increased from $5 \times 10^{-4} \mathrm{M} \mathrm{NaCl}$ to $0.5 \mathrm{M} \mathrm{NaCl}$, the zeta potential of QDs increased from $-27.4 \mathrm{mV}$ to $16.13 \mathrm{mV}$, a finding also observed in other researches $[50,51]$. As the suspension $\mathrm{pH}$ decreased from 8 to 3, the zeta potential of QDs increased from $-42.49 \mathrm{mV}$ to $-2.78 \mathrm{mV}$. It was, therefore, assessed that the various concentrations of QD suspensions that were made using deionized water at $\mathrm{pH} \sim 7$, with estimated $\mathrm{QD}$ aggregates size of $463 \mathrm{~nm}$ and zeta potential of $-53.9 \mathrm{mV}$, provided experimental conditions with maximum stability for QDs with regard to preventing and limiting the formation of QD aggregates, the deposition of QDs at the sand grain surfaces, and the sedimentation of QDs.

3.2. Visualization. The LTFM allowed the visualization of differences between the intensity and the hue among the calibration cells containing QDs in variably saturated porous media. These were differences resulting from transmitted light under fluorescent light exposure and emitted light under UV light exposure, respectively (Tables 1 and 2). The intensity images demonstrated that as the water saturation in the calibration cells increased, more light was transmitted by water through the porous media and that the corresponding intensity images appeared brighter, ranging from shades of gray to white (Table 1). Dry cells had intensity images that appeared black. In the case of saturated porous media, the hue images showed that as the concentration of QDs increased, the fluorescence increased and, therefore, the hue value increased (Table 2). Various shades of green were observed in the corresponding calibration cells. In unsaturated porous media, the emitted light observed in the calibration cells is related to both the water saturation and the concentrations of QDs. The hue image shows that calibration cells with $25 \%$ and $50 \%$ porous media water saturation had hues ranging from red and blue to green as the QD concentrations increased (Table 2). The calibration cells with $75 \%$ porous media water saturation had a hue that ranged from orange and yellow to green as the QD concentrations increased (Table 2). The color difference of the calibration cells with variable water saturation but identical QD concentration suggests that the air saturation and, therefore, the presence of gas-water interfaces and gas-solid interfaces were influencing not only the intensity value of the transmitted light but also the hue value of the emitted light.

The intensity and hue values were obtained from the conversion of the images from RGB to HSI format using the IPLab software. The intensity values ranged from black, the lowest intensity value (12), to white, the highest value (160). The 1976 chromaticity diagram of the Commission Internationale de I'Eclairage was used to display the hue values. The hue ranged from $27^{\circ}$ to $75^{\circ}$ in the case of the saturated porous media and from $75^{\circ}$ to $180^{\circ}$ in the case of the unsaturated porous media. In each cell, the hue and intensity values were almost uniform and there were few differences within the cells.

3.3. Calibration. QD concentrations in variably saturated porous media were determined by deriving relationships from the intensity and hue values resulting from transmitted light and emitted light, respectively, obtained from images of the calibration cells. Two calibrations were performed to determine the water saturation and the QD concentration. The first calibration established the relationship between 
TABLE 1: RGB image and intensity image of the calibration cells under fluorescent light exposure.

\begin{tabular}{|c|c|c|c|c|c|c|c|c|c|c|}
\hline \multirow{3}{*}{$\begin{array}{l}\text { QDS } \\
\text { concentration } \\
\text { (ppm) }\end{array}$} & \multicolumn{10}{|c|}{ Water saturation (\%) } \\
\hline & \multicolumn{2}{|c|}{$0 \%$} & \multicolumn{2}{|c|}{$25 \%$} & \multicolumn{2}{|c|}{$50 \%$} & \multicolumn{2}{|c|}{$75 \%$} & \multicolumn{2}{|c|}{$100 \%$} \\
\hline & $\begin{array}{c}\text { RGB } \\
\text { image }\end{array}$ & $\begin{array}{c}\text { Intensity } \\
\text { image }\end{array}$ & $\begin{array}{c}\text { RGB } \\
\text { image }\end{array}$ & $\begin{array}{c}\text { Intensity } \\
\text { image }\end{array}$ & $\begin{array}{c}\text { RGB } \\
\text { image }\end{array}$ & $\begin{array}{c}\text { Intensity } \\
\text { image }\end{array}$ & $\begin{array}{c}\text { RGB } \\
\text { image }\end{array}$ & $\begin{array}{c}\text { Intensity } \\
\text { image }\end{array}$ & $\begin{array}{c}\text { RGB } \\
\text { image }\end{array}$ & $\begin{array}{c}\text { Intensity } \\
\text { image }\end{array}$ \\
\hline $40 \mathrm{ppm}$ & & & & & & & & & & \\
\hline $100 \mathrm{ppm}$ & & & & & & & & & & \\
\hline $150 \mathrm{ppm}$ & & & & & & & & & & \\
\hline 200 ppm & & & & & & & & & & \\
\hline $300 \mathrm{ppm}$ & & & & & & & & & & \\
\hline $500 \mathrm{ppm}$ & & & & & & & & & & \\
\hline
\end{tabular}

TABLE 2: RGB image and hue image of the calibration cells under UV light exposure.

\begin{tabular}{|c|c|c|c|c|c|c|c|c|c|c|}
\hline \multirow{3}{*}{$\begin{array}{l}\text { QDS } \\
\text { concentration } \\
\text { (ppm) }\end{array}$} & \multicolumn{10}{|c|}{ Water saturation (\%) } \\
\hline & \multicolumn{2}{|c|}{$0 \%$} & \multicolumn{2}{|c|}{$25 \%$} & \multicolumn{2}{|c|}{$50 \%$} & \multicolumn{2}{|c|}{$75 \%$} & \multicolumn{2}{|c|}{$100 \%$} \\
\hline & $\begin{array}{l}\text { RGB } \\
\text { image }\end{array}$ & $\begin{array}{l}\text { Hue } \\
\text { image }\end{array}$ & $\begin{array}{l}\text { RGB } \\
\text { image }\end{array}$ & $\begin{array}{l}\text { Hue } \\
\text { image }\end{array}$ & $\begin{array}{c}\text { RGB } \\
\text { image }\end{array}$ & $\begin{array}{l}\text { Hue } \\
\text { image }\end{array}$ & $\begin{array}{c}\text { RGB } \\
\text { image }\end{array}$ & $\begin{array}{l}\text { Hue } \\
\text { image }\end{array}$ & $\begin{array}{l}\text { RGB } \\
\text { image }\end{array}$ & $\begin{array}{l}\text { Hue } \\
\text { image }\end{array}$ \\
\hline $40 \mathrm{ppm}$ & & & & & & & & & & \\
\hline $100 \mathrm{ppm}$ & & & & & & & & & & \\
\hline $150 \mathrm{ppm}$ & & & & & & & & & & \\
\hline 200 ppm & & & & & & & & & & \\
\hline $300 \mathrm{ppm}$ & & & & & & & & & & \\
\hline $500 \mathrm{ppm}$ & & & & & & & & & & \\
\hline
\end{tabular}

the porous media water saturation of the calibration cells containing a wide range of QD concentrations and the intensity component of the transmitted light obtained by placing a fluorescent light behind the calibration cells. The second calibration assessed the relationship between the QD concentrations and the hue component of the emitted light of the calibration cells resulting from UV light exposure.

The light intensity of the calibration cells containing a wide range of QD concentrations in variably saturated porous media increased as water saturation increased. The mean intensity values calculated for different water saturations containing various QD concentrations are displayed in Figure 2. The error bars representing the standard error of the mean indicated a value of 2.95 in the case of $25 \%$ porous media water saturation and a value of 18.56 in the case of $100 \%$ porous media water saturation. The impacts of the color of QD suspensions on the intensity value of the transmitted light were negligible. The relationship between water saturation and intensity is independent of the QD concentrations in the porous media. These results comply with previous findings demonstrating that light intensity is linearly correlated with water saturation $\left(R^{2}=97.57 \%\right)[45,49,52]$. 


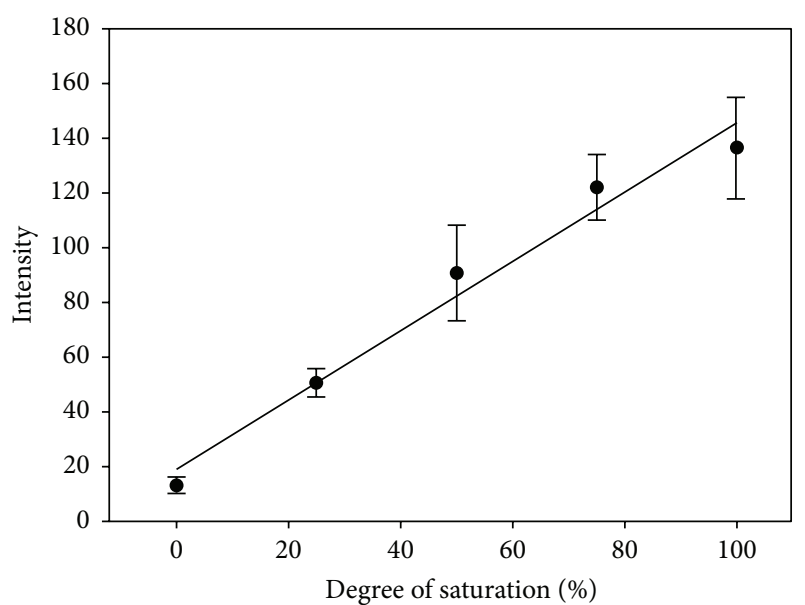

FIGURE 2: Intensity of the light transmitted through variably saturated porous media under fluorescent light exposure as a function of water saturation.

Light intensity and water saturation are uniquely related and can be estimated by

$$
S=S_{S}\left(\frac{I-I_{0}^{\theta}}{I_{S}^{\theta}-I_{0}^{\theta}}\right) \quad \text { with } 0 \leq S \leq S_{S}
$$

where $S$ is the water saturation (\%), $S_{S}$ is the saturated porous media equal to $100 \%, I$ is the intensity of the transmitted light, $I_{0}^{\theta}$ is the intensity value at $0 \%$ water saturation, and $I_{S}^{\theta}$ is the intensity value at $100 \%$ water saturation.

The hue values representative of the QD concentrations of the calibration cells showed two trends in reference to the water saturation scenarios. In saturated porous media conditions, an increase in QD concentration resulted in an increase in the hue value. In the case of unsaturated porous media conditions, on the other hand, an increase in the QD concentrations led to a decrease in the hue value when water saturation was constant. For the same QD concentration, the highest hue value belonged to the cell with the lowest water saturation (25\% saturation), and as the water saturation of the calibrations cells increased, the hue value decreased. The discrepancy between saturated and unsaturated porous media conditions indicated that hue was also impacted by water saturation and therefore intensity. Thus, in the case of variably saturated porous media containing fluorescent nanoparticles (QDs), the light that was emitted was a function not only of the QD fluorescence (and therefore QD concentration), but also of the water saturation or air saturation (i.e., light intensity). The fluorescence of QDs in variably saturated porous media was affected by air saturation; therefore, adjusted hue values were calculated by taking the ratio of the hue value resulting from emitted light under UV exposure and the intensity value resulting from the transmitted light under fluorescent light exposure. The alternately switching on and off of the fluorescent and the UV lights allowed two independent hue and intensity images of the calibration cells to be obtained.
The hue value was not exclusively a function of QD concentrations; it depended on both QD concentrations and water saturations. To account for the effects of water or air saturation in porous media on the emitted fluorescence of QDs, and therefore on the hue detected in the calibrations cells with different QD concentrations, an adjusted hue value (A) resulting from the fluorescence of QDs under both saturated and unsaturated porous media was estimated using a hue-intensity ratio defined as

$$
A=\frac{H}{I}
$$

where $H$ is the hue value of the emitted light from QDs in variably saturated porous media under UV exposure and $I$ is the intensity value of the transmitted light resulting from water in variably saturated porous media under fluorescent light exposure.

The adjusted hue values $(A)$ or the hue-intensity ratio were plotted against QD concentrations for constant water saturations (Figure 3). For variably saturated porous media and for a constant water saturation, a linear relationship between QD concentrations and the adjusted hue values (hue-intensity ratio) was established. It follows that the adjusted hue values $(A)$ or hue-intensity ratio increases as the water saturation decreases, leading to a maximum adjusted hue value $(A)$ or hue-intensity ratio at low saturations, and vice versa. The lines converged at an anchor point $A_{A}$. The slopes of the converging lines are a function of the water saturations.

For constant water saturations, the QD concentration QD (for $\mathrm{QD} \geq 40 \mathrm{ppm}$ ) can be calculated as

$$
\mathrm{QD}=\mathrm{QD}_{40 \mathrm{ppm}}\left(\frac{\left(A-A_{A}\right)}{A_{40 \mathrm{ppm}}(S)}\right),
$$

where $\mathrm{QD}_{40 \mathrm{ppm}}$ is the concentration of QDs in saturated porous media, equal to $40 \mathrm{ppm}, A$ is the adjusted hue value or hue-intensity ratio resulting from measurement of the hue of the emitted light and the intensity of the transmitted light, $A_{A}$ is the adjusted hue value of the anchor point, and $A_{40 \mathrm{ppm}}(S)$ is the adjusted hue value impacted by the water saturation, $S$.

When developing the relationships between $A$ and QD concentrations for constant water saturations, it was observed that the slopes of the different constant water saturations were dissimilar. Further, four different water saturation zones were identified $(0 \% \leq S \leq 25 \%),(25 \%<S \leq 50 \%),(50 \%<S \leq$ $75 \%)$, and $(75 \%<S \leq 100 \%)$. Equations of the adjusted hue value (hue-intensity ratio) $A_{40 \mathrm{ppm}}(S)$ impacted by the water saturation were developed for each of the four different water saturation zones:

$$
\begin{aligned}
& A_{40 \mathrm{ppm}}(S) \\
& =\left(A_{S=25 \%}^{\mathrm{QD}=40 \mathrm{ppm}}-A_{A}\right) \\
& \quad-\left(\frac{S}{S_{25 \%}-S_{0 \%}}\left(A_{S=25 \%}^{\mathrm{QD}=40 \mathrm{ppm}}-A_{S=0 \%}\right)\right) \\
& \quad \text { with }(0 \% \leq S \leq 25 \%),
\end{aligned}
$$




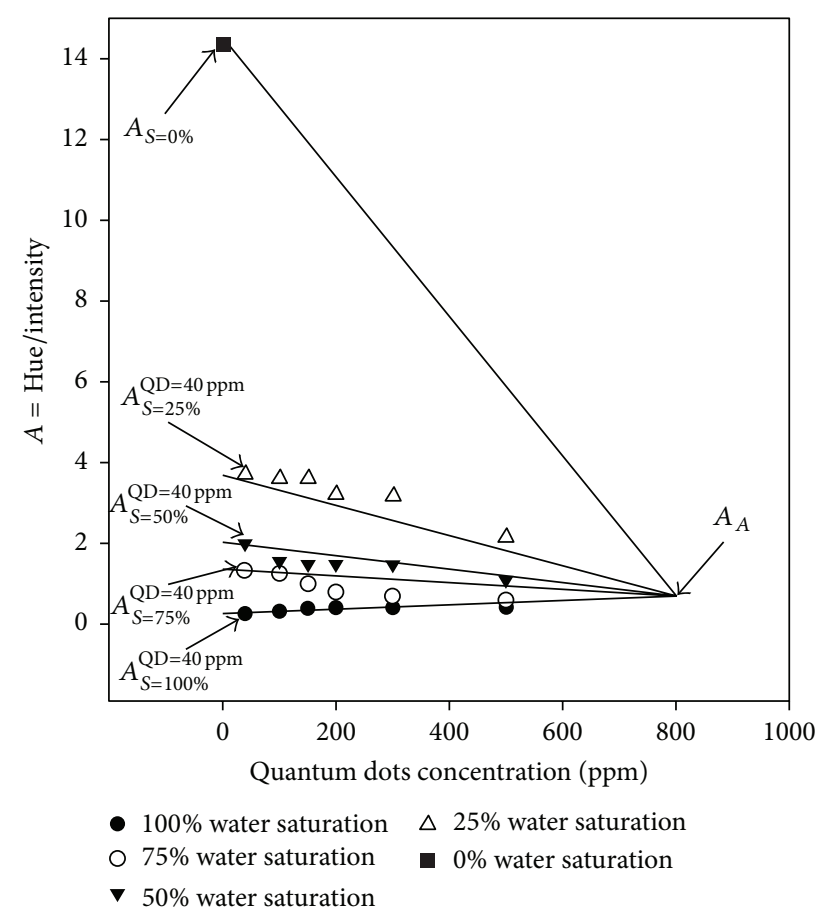

FIGURE 3: Quantum dots concentration versus hue-intensity ratio for constant water saturations in variably saturated porous media.

$$
\begin{aligned}
& A_{40 \mathrm{ppm}}(S) \\
& =\left(A_{S=50 \%}^{\mathrm{QD}=40 \mathrm{ppm}}-A_{A}\right) \\
& \quad-\left(\frac{S}{S_{50 \%}-S_{25 \%}}\left(A_{S=50 \%}^{\mathrm{Q}=40 \mathrm{ppm}}-A_{S=25 \%}^{\mathrm{QD}=40 \mathrm{ppm}}\right)\right) \\
& \text { with }(25 \%<S \leq 50 \%),
\end{aligned}
$$

$$
-\left(\frac{S}{S_{75 \%}-S_{50 \%}}\left(A_{S=75 \%}^{\mathrm{QD}=40 \mathrm{ppm}}-A_{S=50 \%}^{\mathrm{QD}=40 \mathrm{ppm}}\right)\right)
$$$$
\text { with }(50 \%<S \leq 75 \%) \text {, }
$$

$$
\begin{aligned}
& A_{40 \mathrm{ppm}}(S) \\
& =\left(A_{S=100 \%}^{\mathrm{QD}=40 \mathrm{ppm}}-A_{A}\right) \\
& \quad-\left(\frac{S}{S_{100 \%}-S_{75 \%}}\left(A_{S=100 \%}^{\mathrm{QD}=40 \mathrm{ppm}}-A_{S=75 \%}^{\mathrm{QD}=40 \mathrm{ppm}}\right)\right) \\
& \quad \text { with }(75 \%<S \leq 100 \%),
\end{aligned}
$$

where $S$ is the water saturation (\%), $S_{25 \%}, S_{50 \%}, S_{75 \%}$, and $S_{100 \%}$ are the water saturation values at $25 \%, 50 \%, 75 \%$, and $100 \%$, respectively, $A_{A}$ is the adjusted hue value of the anchor point, $A_{S=25 \%}^{\mathrm{QD}=40 \mathrm{ppm}}, A_{S=50 \%}^{\mathrm{QD}=40 \mathrm{ppm}}, A_{S=75 \%}^{\mathrm{QD}=40 \mathrm{ppm}}$, and $A_{S=100 \%}^{\mathrm{QD}=40 \mathrm{ppm}}$ are the adjusted hue values for $25 \%, 50 \%, 75 \%$, and $100 \%$ water saturated cells, respectively, containing a concentration of QDs equal to $40 \mathrm{ppm}$, and $A_{S=0 \%}$ is the adjusted hue value for a $0 \%$ water saturated cell.

In summary, water saturation is determined first with (1), followed by the determination of the QD concentration using (3).

\section{Discussion}

A nonintrusive, highly spatial and temporal light transmission and fluorescence method (LTFM) was developed to visualize and measure in situ concentrations of QD nanoparticles in variably saturated porous media. The LTFM and its calibration procedure provide direct visualization and in situ measurements of QD concentration in variably saturated porous media compared to other methods that may use relative measurements. Although the application of LTFM is limited by the requirement to use translucent porous media, fluorescent nanoparticles, and two-dimensional porous media chambers, visualization of QDs and in situ measurements of QDs in variably saturated porous media by the LTFM allow a quantitative investigation of the mobility and transport of QDs in porous media in situ and in real time to be made, in contrast to traditional column experiments and derived breakthrough curves.

Unsaturated porous media conditions were found to affect the visualization of QDs since their fluorescence is impacted by the water saturation or air saturation; therefore, the hue values resulting from the fluorescence of QDs were adjusted with respect to the intensity values which represent the water saturation or air saturation. Water saturation was directly proportional to the intensity value. A linear relationship was observed between adjusted hue values $(A)$ or hue-intensity ratio values and QD concentrations for constant water saturation. The procedure to quantify QD concentrations in variably saturated porous media includes two steps: first the water saturation in porous media is measured from the intensity value of the transmitted light through the porous media resulting from fluorescent light exposure; then, once the water content is determined, the QD concentrations are obtained from adjusted hue value $(A)$ or hue-intensity ratio value in which the hue value is obtained from the fluorescence or the emitted light of QDs under UV light exposure.

The minimum of the QD nanoparticle concentration that could be detected by the LTFM was estimated at $5 \mathrm{ppm}$ through extensive experimentation. The sensitivity and accuracy of the LTFM can be assessed through the range of $A$ values at QD concentration of $40 \mathrm{ppm}$ that controlled the sensitivity of the equations computing QD concentrations. As the water content increased, the sensitivity and accuracy of the LTFM decreased. For water saturations comprised between $0-25 \%$ and $25-50 \%$, we observed a change of $A$ values of $75 \%$ and $12 \%$, respectively, an indication of some significant sensitivity. For water saturations comprised between $50-75 \%$ and $75-100 \%$, the change in $A$ values was $7 \%$ and $5 \%$, respectively, showing a decrease in sensitivity. A possible improvement of the LTFM for visualization and 
in situ concentration measurements of QDs in terms of enhancing the quantitative procedure may be the use of more refined and specific wavelengths instead of a broad spectrum.

The Beer-Lambert law states that the intensity of the fluorescence is equal to the intensity of the adsorbed light multiplied by the fluorescence quantum yield [53]; however, its application to the light transmission method is complex because of light reflection and fluorescence quantum yield [12]. In addition, loss of light is observed through Fresnel losses at interfaces, such as gas-water, gas-solid (porous matrix), and solid-water interfaces. Interfaces present in these saturated and unsaturated porous media systems play a key role in the light transmission and scattering. Of greater scattering potential is the gas-solid interface of the porous media, as the refractive index contrast gas-solid is far greater than the interface water-solid, such that the quartz sand will scatter more strongly than the gas bubbles, therefore affecting the illumination component contributions to the quantum color fluorescence. Undoubtedly, the gas-water interface contributes also, but less strongly. Methods combining Fresnel losses and the Beer-Lambert Law have been developed and applied to flow in unsaturated porous media systems in homogeneous sands containing gas-water interfaces and soilwater interfaces. As a consequence, calibration curves and empirical equations for visualization were established to quantify the water saturations and the QD concentrations in variably saturated porous media due to porous media characteristics and conditions.

As the QDs' residency in the unsaturated porous media will also potentially influence the light transmission and scattering, it is important to consider where the QDs reside, that is, in the water, at the gas-water interfaces, or at the solid-water interfaces. Previous research has demonstrated that, in unsaturated porous media systems, the primary function of gas-water interfaces is the capture and retention of QDs, while the secondary function is postulated to be the potential transfer of previously captured QDs to solid-water interfaces ensuing their deposition at solid-water interfaces [54]. Other research findings also demonstrate this potential phenomenon in the case of increase in ionic strength, where a change in the controlling process for particles retention in unsaturated porous media from pore straining to capture and retention at gas-water interfaces, and finally deposition at solid-water interfaces, took place [55].

The LTFM may be applied to characterize the mobility and transport of QD nanoparticles in the saturated and unsaturated zones over scales ranging from $\mu \mathrm{m}$ to $\mathrm{cm}$, while simultaneously quantifying the water saturation. This is an important characteristic of the LTFM as it allows the visualization of the whole flow field while measuring in situ concentration of QDs and water saturation. The LTFM is a visualization method allowing the investigation of the dynamic and transient as well as vertical and horizontal flow and transport phenomena, under different solution chemistry and hydrodynamic conditions known to influence the mobility and transport of QDs. As the LTFM allows quantification and visualization of QDs in porous media, it has the potential to elucidate the individual contribution of the mechanisms and environmental parameters affecting their transport and retention. The LTFM may be used to visualize QDs and monitor their transport in the subsurface environment in order to validate fate and transport models of nanoparticles at pore scale and Darcy scale and to assess the risks that nanomaterials present to public health and the environment.

The LTFM may be used to detect light-induced reactive surface chemistry of QDs for environmental sensing implications that use photoluminescence and reactivity. As our research demonstrated the potential of the LTFM to detect and quantify the fluorescence emitted by QDs, changes in the chemical optical properties of reactive QDs as a result of chemical reactions can be detected and monitored in real time by the LTFM. Based on the physicochemical properties of reactive QDs, biochemical changes in the environment that reactive QDs encounter or are placed in may be sensed and monitored through chemical optical detection using the LTFM. Therefore, the coupling of the LTFM as a visualization method and reactive QDs as a smart nanoparticle-sensing technology can be applied to monitor physical, chemical, and biological changes that occur in environmental systems. It has potential applications in the fields of soil, water, and environment quality, as well as environmental remediation and protection of ecosystem and public health. However, the stability of reactive QDs in the environment and their interactions with surfaces and other biochemical compounds from soil, plants, and microorganisms should be further examined and controlled to ensure the integrity and functionality of reactive QDs as smart chemical sensors once they are released into the natural environment. In the natural environment, the LTFM and reactive QDs can be applied to study certain characteristics of natural soils, such as their biochemical characteristics, rather than the behavior of nanomaterials in natural soils due to the soil components that may mask any artificial nanoparticles present in soils. The coupling of the LTFM as a visualization method and reactive QDs as a smart nanoparticle-sensing technology may contribute to the potential applications of QD sensor technology for early detection and warning of the presence of contaminants in the environment and for monitoring of biochemical changes in the environment.

\section{Conclusions}

The LTFM allows the visualization and nonintrusive measurement of in situ concentrations of QDs in variably saturated porous media in real time across the whole experimental field. The LTFM allowed us to visualize and monitor QDs in variably saturated porous media and to acquire water saturations and in situ QD concentration measurements that are key parameters to provide insights into the mechanisms that govern the transport of nanoparticles in the subsurface environment. The ability to visualize QDs in porous media is significant, as the LTFM can provide both quantitative and qualitative data from the in situ research of nanoparticles in environmental matrices under various soil solution chemistry and hydrodynamic conditions. 


\section{Conflict of Interests}

The authors declare that there is no conflict of interests regarding the publication of this paper.

\section{Acknowledgments}

This work was supported primarily by the U.S. Department of Energy, Office of Science, Office of Biological and Environmental Research, Environmental Remediation Sciences Program under Grant no. DE-FG02-06ER64193. The authors thank Solidea Bonina for her technical assistance to this study.

\section{References}

[1] M. C. Roco, "Broader societal issues of nanotechnology," Journal of Nanoparticle Research, vol. 5, no. 3-4, pp. 181-189, 2003.

[2] R. Hardman, "A toxicologic review of quantum dots: toxicity depends on physicochemical and environmental factors," Environmental Health Perspectives, vol. 114, no. 2, pp. 165-172, 2006.

[3] M. R. Wiesner, G. V. Lowry, P. Alvarez, D. Dionysiou, and P. Biswas, "Assessing the risks of manufactured nanomaterials," Environmental Science and Technology, vol. 40, no. 14, pp. 43364345, 2006.

[4] A. M. Derfus, W. C. W. Chan, and S. N. Bhatia, "Probing the cytotoxicity of semiconductor quantum dots," Nano Letters, vol. 4, no. 1, pp. 11-18, 2004.

[5] P. Biswas and C.-Y. Wu, "Critical Review: nanoparticles and the environment," Journal of the Air \& Waste Management Association, vol. 55, no. 6, pp. 708-746, 2005.

[6] K. A. D. Guzmán, M. R. Taylor, and J. F. Banfield, "Environmental risks of nanotechnology: national nanotechnology initiative funding, 2000-2004," Environmental Science \& Technology, vol. 40, no. 5, pp. 1401-1407, 2006.

[7] W.-X. Zhang, "Nanoscale iron particles for environmental remediation: an overview," Journal of Nanoparticle Research, vol. 5, no. 3-4, pp. 323-332, 2003.

[8] H. F. Lecoanet, J.-Y. Bottero, and M. R. Wiesner, "Laboratory assessment of the mobility of nanomaterials in porous media," Environmental Science and Technology, vol. 38, no. 19, pp. 51645169, 2004.

[9] H. F. Lecoanet and M. R. Wiesner, "Velocity effects on fullerene and oxide nanoparticle deposition in porous media," Environmental Science \& Technology, vol. 38, no. 16, pp. 4377-4382, 2004.

[10] C. J. G. Darnault, P. Garnier, Y.-J. Kim et al., "Preferential transport of Cryptosporidium parvum oocysts in variably saturated subsurface environments," Water Environment Research, vol. 75, no. 2, pp. 113-120, 2003.

[11] C. J. G. Darnault, T. S. Steenhuis, P. Garnier et al., "Preferential flow and transport of cryptosporidium parvum oocysts through the vadose zone: experiments and modeling," Vadose Zone Journal, vol. 3, no. 1, pp. 262-270, 2004.

[12] P. F. Zhang and Y. G. Wang, "Epi-fluorescence imaging of colloid transport in porous media at decimeter scales," Environmental Science \& Technology, vol. 40, no. 19, pp. 6064-6069, 2006.

[13] S. Sirivithayapakorn and A. Keller, "Transport of colloids in unsaturated porous media: a pore-scale observation of processes during the dissolution of air-water interface," Water Resources Research, vol. 39, no. 12, 2003.
[14] M. Auset and A. A. Keller, "Pore-scale processes that control dispersion of colloids in saturated porous media," Water Resources Research, vol. 40, no. 3, 2004.

[15] J. T. Crist, J. F. McCarthy, Y. Zevi, P. Baveye, J. A. Throop, and T. S. Steenhuis, "Pore-scale visualization of colloid transport and retention in partly saturated porous media," Vadose Zone Journal, vol. 3, no. 2, pp. 444-450, 2004.

[16] G. Chen and M. Flury, "Retention of mineral colloids in unsaturated porous media as related to their surface properties," Colloids and Surfaces A: Physicochemical and Engineering Aspects, vol. 256, no. 2-3, pp. 207-216, 2005.

[17] C. J. Werth, C. Zhang, M. L. Brusseau, M. Oostrom, and T. Baumann, "A review of non-invasive imaging methods and applications in contaminant hydrogeology research," Journal of Contaminant Hydrology, vol. 113, no. 1-4, pp. 1-24, 2010.

[18] J. W. Bridge, S. A. Banwart, and A. L. Heathwaite, "Noninvasive quantitative measurement of colloid transport in mesoscale porous media using time lapse fluorescence imaging," Environmental Science and Technology, vol. 40, no. 19, pp. 5930-5936, 2006.

[19] D. A. DiCarlo, Y. Zevi, A. Dathe, S. Giri, B. Gao, and T. S. Steenhuis, "In situ measurements of colloid transport and retention using synchrotron X-ray fluorescence," Water Resources Research, vol. 42, no. 12, Article ID W12S05, 2006.

[20] X. Li, C.-L. Lin, I. D. Miller, and W. P. Johnson, "Porescale observation of microsphere deposition at grain-to-grain contacts over assemblage-scale porous media domains using X-ray microtomography," Environmental Science \& Technology, vol. 40, no. 12, pp. 3762-3768, 2006.

[21] P. Klauth, R. Bauer, C. Ralfs et al., "Fluorescence macrophotography as a tool to visualise and quantify spatial distribution of deposited colloid tracers in porous media," Colloids and Surfaces A: Physicochemical and Engineering Aspects, vol. 306, no. 1-3, pp. 118-125, 2007.

[22] J. L. Nadeau, N. N. Perreault, T. D. Niederberger, L. G. Whyte, H. J. Sun, and R. Leon, "Fluorescence microscopy as a tool for in situ life detection," Astrobiology, vol. 8, no. 4, pp. 859-874, 2008.

[23] A. P. Alivisatos, "Perspectives on the physical chemistry of semiconductor nanocrystals," The Journal of Physical Chemistry, vol. 100, no. 31, pp. 13226-13239, 1996.

[24] M. Bruchez Jr., M. Moronne, P. Gin, S. Weiss, and A. P. Alivisatos, "Semiconductor nanocrystals as fluorescent biological labels," Science, vol. 281, no. 5385, pp. 2013-2016, 1998.

[25] B. Ballou, B. C. Lagerholm, L. A. Ernst, M. P. Bruchez, and A. S. Waggoner, "Noninvasive imaging of quantum dots in mice," Bioconjugate Chemistry, vol. 15, no. 1, pp. 79-86, 2004.

[26] D. S. Lidke and D. J. Arndt-Jovin, "Imaging takes a quantum leap," Physiology, vol. 19, no. 6, pp. 322-325, 2004.

[27] A. M. Smith and S. M. Nie, "Chemical analysis and cellular imaging with quantum dots," Analyst, vol. 129, no. 8, pp. 672$677,2004$.

[28] M. Ikanovic, W. E. Rudzinski, J. G. Bruno et al., "Fluorescence assay based on aptamer-quantum dot binding to Bacillus thuringiensis spores," Journal of Fluorescence, vol. 17, no. 2, pp. 193-199, 2007.

[29] P. D. Zhang, L. A. Li, C. Q. Dong, H. F. Qian, and J. C. Ren, "Sizes of water-soluble luminescent quantum dots measured by fluorescence correlation spectroscopy," Analytica Chimica Acta, vol. 546, no. 1, pp. 46-51, 2005.

[30] C. B. Murray, D. J. Norris, and M. G. Bawendi, "Synthesis and characterization of nearly monodisperse $\mathrm{CdE}(\mathrm{E}=\mathrm{S}$, Se, 
Te) semiconductor nanocrystallites," Journal of the American Chemical Society, vol. 115, no. 19, pp. 8706-8715, 1993.

[31] X. H. Zhong, Y. Y. Feng, W. Knoll, and M. Y. Han, "Alloyed $\mathrm{Zn}_{\mathrm{x}} \mathrm{Cd}_{1-\mathrm{x}} \mathrm{S}$ nanocrystals with highly narrow luminescence spectral width," Journal of the American Chemical Society, vol. 125, no. 44, pp. 13559-13563, 2003.

[32] X. H. Zhong, M. Y. Han, Z. L. Dong, T. J. White, and W. Knoll, "Composition-tunable $Z n_{x} C d_{1-x}$ Se nanocrystals with high luminescence and stability," Journal of the American Chemical Society, vol. 125, no. 28, pp. 8589-8594, 2003.

[33] S. Kim, B. Fisher, H. Y. Eisler, and M. G. Bawendi, "Type-II quantum dots: $\mathrm{CdTe} / \mathrm{CdSe}$ (core/shell) and CdSe/ZnTe(Core/ Shell) heterostructures," Journal of the American Chemical Society, vol. 125, no. 38, pp. 11466-11467, 2003.

[34] A. P. Alivisatos, T. D. Harris, P. J. Carroll, M. L. Steigerwald, and L. E. Brus, "Electron-vibration coupling in semiconductor clusters studied by resonance Raman spectroscopy," The Journal of Chemical Physics, vol. 90, no. 7, pp. 3463-3468, 1989.

[35] M. G. Bawendi, M. L. Steigerwald, and L. E. Brus, "The quantum-mechanics of larger semiconductor clusters ('Quantum Dots')," Annual Review of Physical Chemistry, vol. 41, no. 1, pp. 477-496, 1990.

[36] M. G. Bawendi, W. L. Wilson, L. Rothberg et al., "Electronic structure and photoexcited-carrier dynamics in nanometer-size CdSe clusters," Physical Review Letters, vol. 65, no. 13, pp. 1623$1626,1990$.

[37] M. A. Hines and P. Guyot-Sionnest, "Synthesis and characterization of strongly luminescing ZnS-capped CdSe nanocrystals," Journal of Physical Chemistry, vol. 100, no. 2, pp. 468-471, 1996.

[38] D. J. Norris and M. G. Bawendi, "Measurement and assignment of the size-dependent optical spectrum in CdSe quantum dots," Physical Review B, vol. 53, no. 24, pp. 16338-16346, 1996.

[39] S. Coe-Sullivan, "Inorganic materials efficiently power flatpanel displays," Laser Focus World, vol. 43, no. 3, pp. 65-68, 2007.

[40] S. Coe-Sullivan, "Quantum dot developments," Nature Photonics, vol. 3, no. 6, pp. 315-316, 2009.

[41] Z. A. Peng and X. Peng, "Formation of high-quality CdTe, CdSe, and $\mathrm{CdS}$ nanocrystals using $\mathrm{CdO}$ as precursor," Journal of the American Chemical Society, vol. 123, no. 1, pp. 183-184, 2001.

[42] B. R. Fisher, H.-J. Eisler, N. E. Stott, and M. G. Bawendi, "Emission intensity dependence and single-exponential behavior in single colloidal quantum dot fluorescence lifetimes," Journal of Physical Chemistry B, vol. 108, no. 1, pp. 143-148, 2004.

[43] J. S. Steckel, J. P. Zimmer, S. Coe-Sullivan, N. E. Stott, V. Bulović, and M. G. Bawendi, "Blue luminescence from (CdS)ZnS coreshell nanocrystals," Angewandte Chemie-International Edition, vol. 43, no. 16, pp. 2154-2158, 2004.

[44] C. J. G. Darnault, J. A. Throop, D. A. Dicarlo, A. Rimmer, T. S. Steenhuis, and J.-Y. Parlange, "Visualization by light transmission of oil and water contents in transient two-phase flow fields," Journal of Contaminant Hydrology, vol. 31, no. 3-4, pp. 337-348, 1998.

[45] C. J. G. Darnault, D. A. DiCarlo, T. W. J. Bauters et al., "Measurement of fluid contents by light transmission in transient threephase oil-water-air systems in sand," Water Resources Research, vol. 37, no. 7, pp. 1859-1868, 2001.

[46] R. I. Al-Raoush and C. S. Willson, "A pore-scale investigation of a multiphase porous media system," Journal of Contaminant Hydrology, vol. 77, no. 1-2, pp. 67-89, 2005.

[47] A. Wilson, "What is color?" Electronic Systems Design Magazine, vol. 38, p. 4, 1988.
[48] J. C. Waters and T. E. Wittmann, Quantitative Imaging in Cell Biology, Academic Press, San Diego, Calif, USA, 2014.

[49] N. T. Hoa, "A new method allowing the measurement of rapid variations of the water content in sandy porous media," Water Resources Research, vol. 17, no. 1, pp. 41-48, 1981.

[50] Y. Zhang, Y. Chen, P. Westerhoff, and J. C. Crittenden, "Stability and removal of water soluble CdTe quantum dots in water," Environmental Science \& Technology, vol. 42, no. 1, pp. 321-325, 2008.

[51] I. R. Quevedo and N. Tufenkji, "Influence of solution chemistry on the deposition and detachment kinetics of a CdTe quantum dot examined using a quartz crystal microbalance," Environmental Science \& Technology, vol. 43, no. 9, pp. 3176-3182, 2009.

[52] P. J. Van Geel and J. F. Sykes, "Laboratory and model simulations of a LNAPL spill in a variably-saturated sand, 1. Laboratory experiment and image analysis techniques," Journal of Contaminant Hydrology, vol. 17, no. 1, pp. 1-25, 1994.

[53] R. S. Longhurst, Geometrical and Physical Optics, Longman, London, UK, 1973.

[54] B. Uyusur, C. J. G. Darnault, P. T. Snee, E. Kokën, A. R. Jacobson, and R. R. Wells, "Coupled effects of solution chemistry and hydrodynamics on the mobility and transport of quantum dot nanomaterials in the vadose zone," Journal of Contaminant Hydrology, vol. 118, no. 3-4, pp. 184-198, 2010.

[55] J. E. Saiers and J. J. Lenhart, "Ionic-strength effects on colloid transport and interfacial reactions in partially saturated porous media," Water Resources Research, vol. 39, no. 9, pp. SBH81SBH813, 2003. 

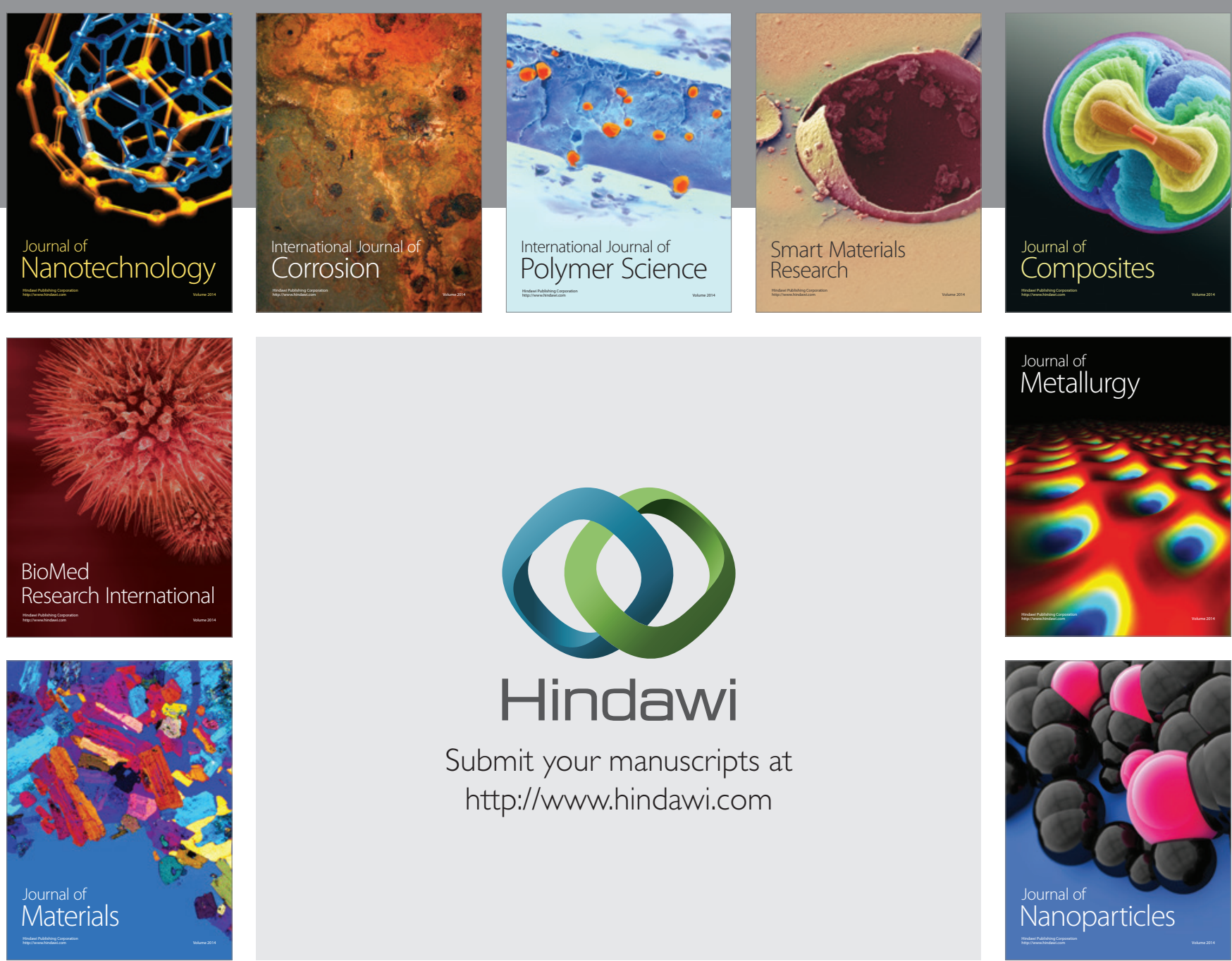

\section{Hindawi}

Submit your manuscripts at

http://www.hindawi.com

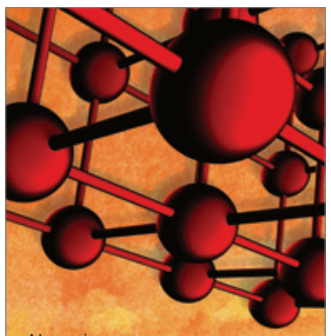

Materials Science and Engineering
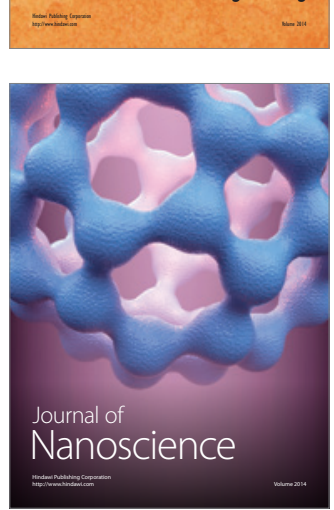
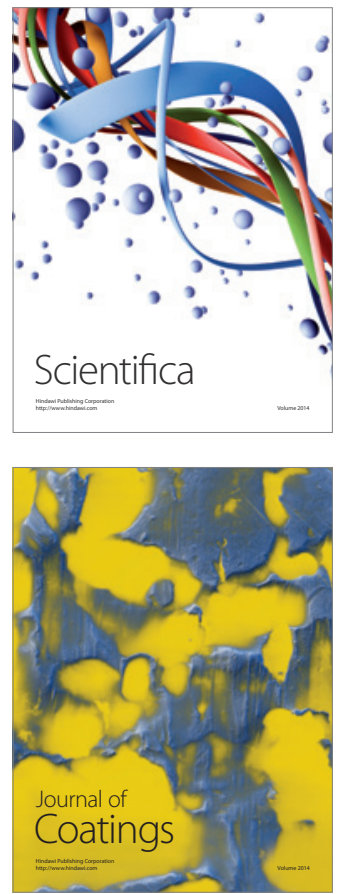
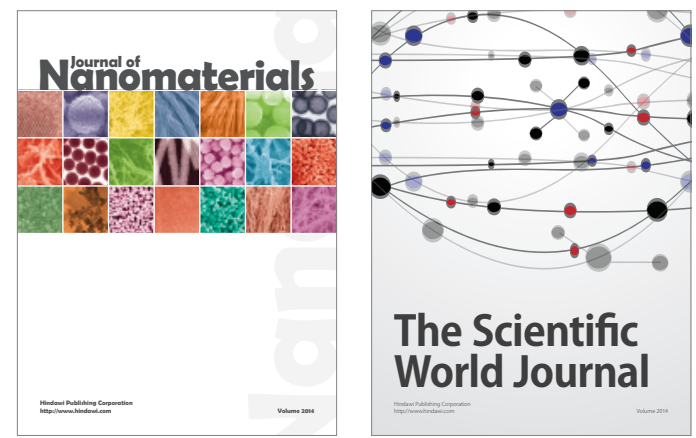

The Scientific World Journal
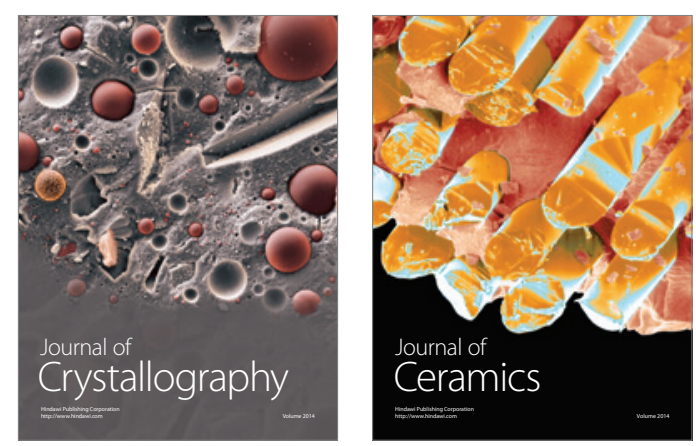
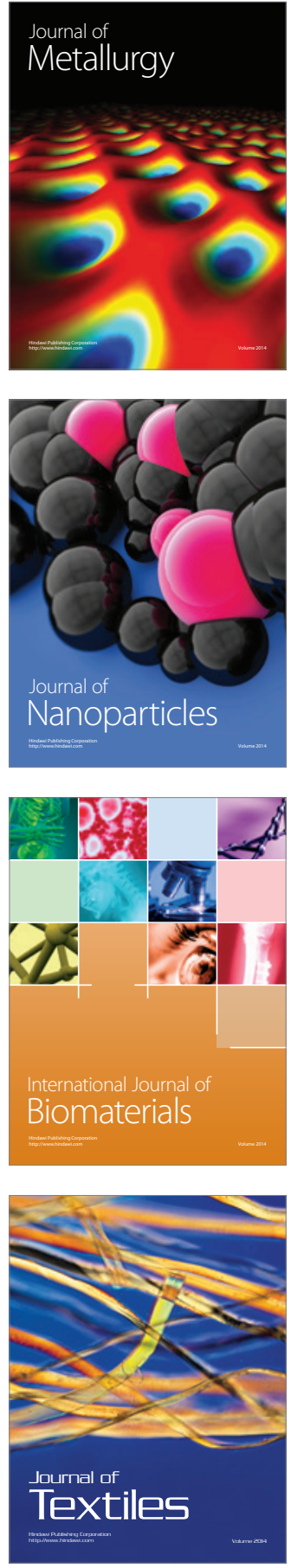